\title{
Preparation and Characterization of Spherical Polymer Packings from $N, N$-Dialkylacrylamide for Reversed-Phase Liquid Chromatography
}

\author{
Shoji Nagaoka, Hirotaka Ihara, and Chuichi Hirayama* \\ Department of Applied Chemistry, Faculty of Engineering \\ Kumamoto University, Kumamoto 860, Japan
}

(Received November 24, 1992)

\begin{abstract}
Chemically stable, totally organic polymer packings were prepared using newly developed $N, N$-dialkylacrylamides and their chromatographic properties were examined. The polymer packings were composed of $N$-methyl $N$-octadecylacrylamide as a hydrophobic moiety and $N, N^{\prime}$-diacrylo- $N, N^{\prime}$-dibutyl-1,6-diaminohexane as a crosslinking monomer. The melting points of both monomers were much lower than those of conventional acrylamide and methacrylamide monomers e.g., $N$-octadecylmethacrylamide, $N, N^{\prime}$-butylenebis(methacrylamide) and $N, N^{\prime}$ methylenebis(acrylamide). This property increased misicibility among the monomers and mode possible suspension copolymerization without use of a third solvent, which would have lowered the mechanical strength of the polymer obtained. The hydrophobicity of the particles prepared by suspension copolymerization was controlled by the monomer ratio in the polymerization. In the liquid chromatography, the column with polymer particles showed normal reversed-phase liquid chromatographic separations for alkanes, alcohols and aromatic hydrocarbons. In addition, the packings did not show abnormal adsorption for ionic substances because they were ion free, and showed no peak tailing for carbonyl compounds because of their lack of amide protons.
\end{abstract}

KEY WORDS Acrylamide/Suspension Polymerization/Porous Spherical Particle / Liquid Chromatography /

Totally organic stationary phases should be better than as reversed-phase liquid chromatography (RPLC) packings alkylated silica gels with abnormal adsorption ${ }^{1-4}$ for ionic compounds due to residual silanol groups and metal impurities. However, conventional polymer packings still show abnormal adsorptions for solutes. This undesirable chromatographic behavior is derived from the aromaticity and basic property of the crosslinking monomers used, e.g., divinylbenzene ${ }^{5,6}$ and triallyl isocyanurate. ${ }^{7}$ On the other hand, ethylene glycol dimethacrylate and $N, N^{\prime}$ methylenebis(acrylamide) ${ }^{8-13}$ are also useful as crosslinking monomers. However, these monomers show some defects, for example, instability in an alkaline solution and less solubility in the polymerization process, respectively. Therefore, it is necessary to develop a new crosslinking monomer for RPLC packings. In this study, we newly synthesized $N, N$-dialkylacrylamide derivatives showing some advantageous properties: (1) the monomers show lower melting points compared with corresponding $\mathrm{N}$-monoalkyl derivatives. This property increases miscibility among monomers. (2) The monomers have no amide proton which causes undesirable bonding interactions for solutes. (3) The monomers show good alkali-resistance. In addition, the polymer particles obtained from these monomers did not show either abnormal retention or peak tailing for ionic compounds, because they had no ionic groups. In this paper, we

\footnotetext{
* To whom corresponding should be addressed.
} 


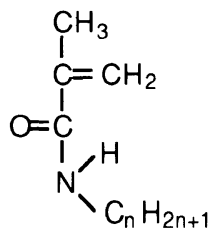

CnH-MAA ( $n=4$ and 18)<smiles>C=C(C)CCCCCCNC(=O)C(=C)C</smiles>

DMAA

$N$-alkylmethacrylamide<smiles>C=CC(=O)N(C)CCCCCCCCCCCC</smiles>

$N, N$-dialkylacrylamide<smiles>C=CC(=O)N(CC)CCN(CCCC)C(=O)C=C</smiles>

Scheme 1. Structures of the monomers used.

describe the preparation and characterization of $N, N$-dialkylacrylamides and their spherical polymers as RPLC packings.

\section{EXPERIMENTAL}

\section{Synthesis of Monomers}

$\mathrm{N}$-Methyl-N-octadecylacrylamide $\left(\mathrm{C}_{18} \mathrm{C}_{1}\right.$ $A A)$. $N$-Methyl- $N$-octadecylamine $(10 \mathrm{~g}, 35.4$ $\mathrm{mmol})$ and triethylamine $(4.4 \mathrm{~g}, 43.4 \mathrm{mmol})$ were dissolved to dry tetrahydrofuran $(100 \mathrm{ml})$. Acryloyl chloride $(3.5 \mathrm{~g}, 38.7 \mathrm{mmol})$ in dry tetrahydrofuran $(100 \mathrm{ml})$ was added dropwise to the solution, stirring at $0^{\circ} \mathrm{C}$. After stirring for $12 \mathrm{~h}, N, N$-diethylamino-propylamine $(5.1$ $\mathrm{g}, 39.2 \mathrm{mmol}$ ) was added to the solution, the precipitates were removed by filtration. The filtrate was washed with $1 N \mathrm{HCl}, 1 N \mathrm{NaOH}$ and water. After being dried over $\mathrm{Na}_{2} \mathrm{SO}_{4}$, the solution was concentrated in vacuo. The yield was $77 \%,{ }^{1} \mathrm{H}$ NMR $\delta\left(\mathrm{CDCl}_{3}, \mathrm{ppm}\right)$ : $0.85\left(\mathrm{~m}, 3 \mathrm{H}, \mathrm{CH}_{3}\right), 1.25\left(\mathrm{~m}, 30 \mathrm{H}, 15 \mathrm{CH}_{2}\right)$, $1.55\left(\mathrm{~s}, 2 \mathrm{H}, \mathrm{CH}_{2}\right), 2.9-3.1\left(\mathrm{~d}, 3 \mathrm{H}, \mathrm{CH}_{3}\right), 5.65$ $(\mathrm{d}, 1 \mathrm{H},=\mathrm{CH}), 6.22-6.64\left(\mathrm{~m}, 2 \mathrm{H},=\mathrm{CH}_{2}\right)$.
Elemental analysis (\%): Found: $\mathrm{C}=76.7$, $\mathrm{H}=12.5, \mathrm{~N}=3.9$; Calcd. for $\mathrm{C}_{22} \mathrm{H}_{43} \mathrm{NO}$ : $\mathrm{C}=78.3, \mathrm{H}=12.7, \mathrm{~N}=4.2$.

$N$-Methyl $N$-Octadecylmethacrylamide $\left(C_{18} C_{1}-M A A\right) . \mathrm{C}_{18} \mathrm{C}_{1}$-MAA was synthesized using $N$-methyl- $N$-octadecylamine and methacryloyl chloride according to a procedure similar to that for the synthesis of $\mathrm{C}_{18} \mathrm{C}_{1}$-AA. The yield was $70 \% .{ }^{1} \mathrm{H} \mathrm{NMR}\left(\mathrm{CDCl}_{3}, \delta \mathrm{ppm}\right)$ : $0.85\left(\mathrm{~m}, 3 \mathrm{H}, \mathrm{CH}_{3}\right), 1.25\left(\mathrm{~m}, 30 \mathrm{H}, 15 \mathrm{CH}_{2}\right)$, $1.55\left(\mathrm{~s}, 2 \mathrm{H}, \mathrm{CH}_{2}\right), 1.95\left(\mathrm{~s}, 3 \mathrm{H}, \mathrm{CH}_{3}\right), 2.90$ $2.95\left(\mathrm{~d}, 3 \mathrm{H}, \mathrm{CH}_{3}\right), 3.30-3.40\left(\mathrm{~d}, 2 \mathrm{H}, \mathrm{CH}_{2}\right)$, $5.00-5.20\left(\mathrm{~m}, 2 \mathrm{H},=\mathrm{CH}_{2}\right)$. Elemental analysis (\%): Found: $\mathrm{C}=78.6, \mathrm{H}=12.8, \mathrm{~N}=4.0$; Calcd. for $\mathrm{C}_{23} \mathrm{H}_{45} \mathrm{NO}$ : $\mathrm{C}=78.0, \mathrm{H}=12.8$, $\mathrm{N}=4.0$.

$N$-Octadecylmethacrylamide $\left(C_{18} H-M A A\right)$ and $N$-Butylmethacrylamide $\left(C_{4} H\right.$-MAA $)$. $\mathrm{C}_{18} \mathrm{H}-\mathrm{MAA}$ and $\mathrm{C}_{4} \mathrm{H}$-MAA were obtained from Kojin Co., Ltd. and used after recrystallization from methanol.

$N, N^{\prime}$-Diacrylo $N, N^{\prime}$-dibutyl 1,6-diaminohexane $\left(2 C_{4}-D A A\right), N, N^{\prime}$-Diacrylo $N, N^{\prime}$-dibutyl 1,6-diaminohexane was prepared by reaction 
between 1-aminobutane and 1,6-dibromohexane. $2 \mathrm{C}_{4}$-DAA was synthesized using $N, N^{\prime}$ dibutyl-1,6-diaminohexane and acryloyl chloride according to a procedure similar to that for the synthesis of $\mathrm{C}_{18} \mathrm{C}_{1}-\mathrm{AA}$. The yield was $32.0 \%{ }^{1} \mathrm{H} \mathrm{NMR}\left(\mathrm{CDCl}_{3}, \delta \mathrm{ppm}\right): 0.85(\mathrm{~m}, 3 \mathrm{H}$, $\left.2 \mathrm{CH}_{3}\right), 1.25-1.40\left(\mathrm{~m}, 8 \mathrm{H}, 4 \mathrm{CH}_{2}\right), 1.40-1.60$ $\left(8 \mathrm{H}, \mathrm{m}, 4 \mathrm{CH}_{2}\right), 5.65(\mathrm{~d}, 2 \mathrm{H},=\mathrm{CH}), 6.3-6.6$ $(\mathrm{m}, 4 \mathrm{H}, 2=\mathrm{CH})$. Elemental analysis $(\%)$ : Found: $\mathrm{C}=70.5, \mathrm{H}=10.8, \mathrm{~N}=8.1$; Calcd. for $\mathrm{C}_{22} \mathrm{H}_{40} \mathrm{O}_{2}: \mathrm{C}=71.4, \mathrm{H}=10.7, \mathrm{~N}=8.3$.

$N, N^{\prime}$-Butylenebis (methacrylamide) (DMAA). $N, N^{\prime}$-Butylenebis(methacrylamide) (DMAA) was obtained from Kojin Co., Ltd. and used after recrystallization from methanol.

\section{Preparation of Polymer Particles}

$\mathrm{C}_{18} \mathrm{C}_{1}$-AA, 2C $\mathrm{C}_{4}$-DAA, diethylbenzene, and 2,2'-azobis(isobutyronitrile) (AIBN) were mixed at room temperature. The mixture was added to an aqueous solution containing $2 \mathrm{wt} \%$ poly(vinyl alcohol) (GH-20, Gohsenol) and suspended by stirring. The suspension was heated at $80^{\circ} \mathrm{C}$ for $24 \mathrm{~h}$ under $\mathrm{N}_{2}$ gas atmosphere. The copolymer particles obtained were washed successively with water, hot water, methanol and acetone. Similarly, spherical polymer particles were obtained using $\quad N$-octadecylmethacrylamide $\left(\mathrm{C}_{18} \mathrm{H}\right.$ MAA),$N$-butylmethacrylamide $\left(\mathrm{C}_{4} \mathrm{H}\right.$-MAA), and ethylene glycol dimethacrylate (EGDM, Nippon Oil \& Fats Co., Ltd.). Particles with diameters of $5-15 \mu \mathrm{m}$ were obtained by adjusting the stirring speed.

\section{Chromatography}

A slurry of $2.5 \mathrm{~g}$ of the beads in $25 \mathrm{ml}$ of methanol was packed into a stainless steel column $(150 \times 4.6 \mathrm{~mm}$ i.d. $)$. As a reference column, ODS (Unisil Pack QC18 $(250 \times 4.6$ $\mathrm{mm}$ i.d.), 12500 theoretical plate numbers and Inertsil $(150 \times 4.6 \mathrm{~mm}$ i.d. $))$ were purchased from GL Science Co., Ltd. Asahipak ODP and $\mathrm{C}_{4} \mathrm{P}$ as alkyl bonded polymer packings were also purchased. The chromatograph included a JASCO 880-PU pump, an UV-VIS
Shimadzu photodiode array SPD-M6A and a Shodex refracto monitor SE-51. A $5 \mu$ l portion of the sample dissolved in an eluent (1.0 $\mathrm{mg} \mathrm{ml}^{-1}$ ) was injected through a Rheodine Model 7125 injector. All chromatography was carried out at $25^{\circ} \mathrm{C}$.

\section{Other Measurements}

Differential scanning calorimetry (DSC) of the monomers prepared was carried out using a heating rate of $5^{\circ} \mathrm{C} \mathrm{min}{ }^{-1}$ with a Seiko I \& E SSC-580 with a DSC-10 instrument. The polymerization of monomers was followed by ${ }^{1} \mathrm{H}$ NMR spectroscopy using a JEOL GX-400. Surface area analysis of the particles was carried out by Brunau-Emmet-Teller (BET) method using a Microtac Model 4200. Scanning electron micrographs of the particles were obtained using a JEOL JSM-840, and IR spectroscopies of the particles were carried out using a Perkin-Elmer 1640 Spectroscopy.

\section{RESULTS AND DISCUSSION}

\section{Characterization of Monomers}

Table I shows the melting points of monomers (peak-top temperature measured by DSC). $N, N$-Dialkylated acryloyl and methacryloyl monomers showed much lower melting points than those of corresponding $\mathrm{N}$-monoalkylated monomers. This is favorable for making spherical particles, because a higher melting point often lowers solubility and miscibility among monomers in suspension copolymerization. When an additional solvent is used in the polymerization process to dissolve monomers, the more the amount used, the softer are the particles produced.

The polymerization properties of the monomers were examined by solution polymerization using AIBN. Monomers were dissolved in diethylbenzene, and heated at $80^{\circ} \mathrm{C}$. The polymerization procedure was followed by ${ }^{1} \mathrm{H}$ NMR spectroscopy. $\mathrm{C}_{18} \mathrm{H}-\mathrm{MAA}$ and $\mathrm{C}_{18} \mathrm{C}_{1}$-AA showed rapid decrease of $\mathrm{CH}_{2}=$ $\mathrm{CH}$ protons with increase of $\mathrm{CH}_{2}-\mathrm{C}$ 
Table I. Preparation of polymer particles

\begin{tabular}{ccccccc}
\hline & & \multicolumn{5}{c}{ Molar ratio } \\
\cline { 3 - 7 } Packings & Type & $\mathrm{C}_{18} \mathrm{C}_{\mathbf{1}}$-AA & $2 \mathrm{C}_{4}$-DAA & $\mathrm{C}_{18}$ H-MAA & C ${ }_{4}$ H-MAA & EGDM \\
\hline DAA-1 & $N, N$-Dialkyl & 0 & 100 & 0 & 0 & 0 \\
DAA-2 & $N, N$-Dialkyl & 30 & 70 & 0 & 0 & 0 \\
DAA-3 & $N, N$-Dialkyl & 40 & 60 & 0 & 0 & 0 \\
DAA-4 & $N, N$-Dialkyl & 50 & 50 & 0 & 0 & 0 \\
AMA-1 & $N$-Alkyl & 0 & 0 & 30 & 20 & 50 \\
\hline
\end{tabular}

Table II. Melting points of monomers

\begin{tabular}{lcc}
\hline Type & Monomer & $\mathrm{mp} /{ }^{\circ} \mathrm{C}$ \\
\hline$N, N$-Dialkyl & $2 \mathrm{C}_{4}$-DAA & $<-100$ \\
& $\mathrm{C}_{18} \mathrm{C}_{1}$-MAA & $29-30$ \\
& $\mathrm{C}_{18} \mathrm{C}_{1}$-AA & $28-30$ \\
\hline$N$-Alkyl & DMAA & $128-129$ \\
& $\mathrm{C}_{18}$ H-MAA & $66-67$ \\
\hline
\end{tabular}

protons. $\mathrm{C}_{18} \mathrm{C}_{1}$-MAA showed no decrease of $\mathrm{CH}_{2}=\mathrm{C}\left(\mathrm{CH}_{3}\right)$ protons, and the polymer was not obtained. $N, N$-Dialkylated methacryloyl monomers are much crowded around $\mathrm{C}_{2}=$ $\mathrm{C}\left(\mathrm{CH}_{3}\right)$ according to their $\mathrm{CPK}$ models. Therefore, acryl derivatives were examined further in this study.

\section{Preparation of Polymer Particles}

Polymer particles, abbreviated in Table II, were prepared by suspension polymerization under the conditions specified. Figure 1 shows a typical electron micrograph of polymer particles prepared from DAA-1 with diameters of $5-15 \mu \mathrm{m}$. The particles are perfectly spherical. The IR spectra showed adsorptions due to $v_{\mathrm{CH}_{2}}$ and $v_{\mathrm{C}=\mathrm{O}}$ at $2920 \mathrm{~cm}^{-1}$ and 1638 $\mathrm{cm}^{-1}$, respectively. Figure 2 shows the relationship between the molar ratio of $\mathrm{C}_{18} \mathrm{C}_{1}-\mathrm{AA}$ in the suspension and the carbon content of the polymer particles obtained. The carbon content increased with the molar ratio of $\mathrm{C}_{18} \mathrm{C}_{1}$-AA. This indicates that the hydrophobicity of the packings is easily controllable by the molar ratio in suspension polymeriza-

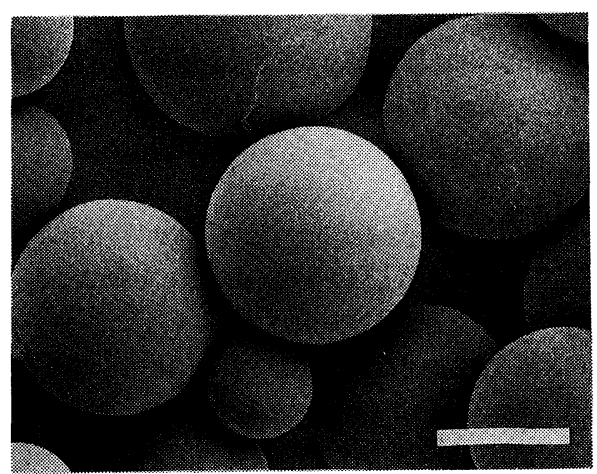

Figure 1. Scanning electron micrographs of particles (DAA-1). A scale bar presents $10 \mu \mathrm{m}$.

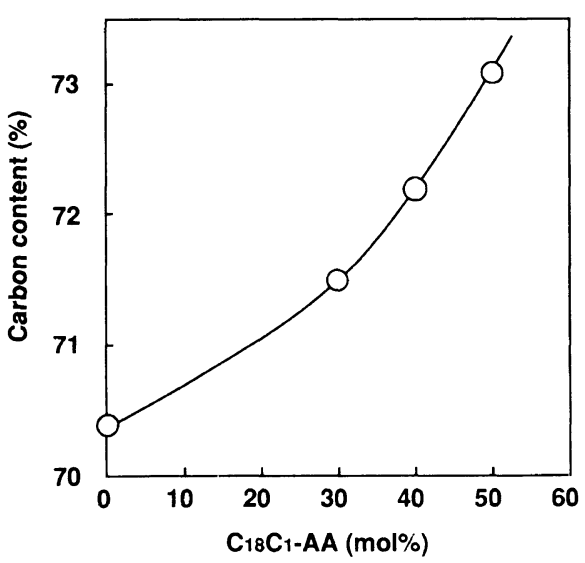

Figure 2. Relationship between molar ratios of $\mathrm{C}_{18} \mathrm{C}_{1}$ AA monomer and carbon contents of particles.

tion, as the hydrophobicity of packings is directly related to the retention ability in the liquid chromatography process.

The pore size of $N, N$-dialkyl type polymer 


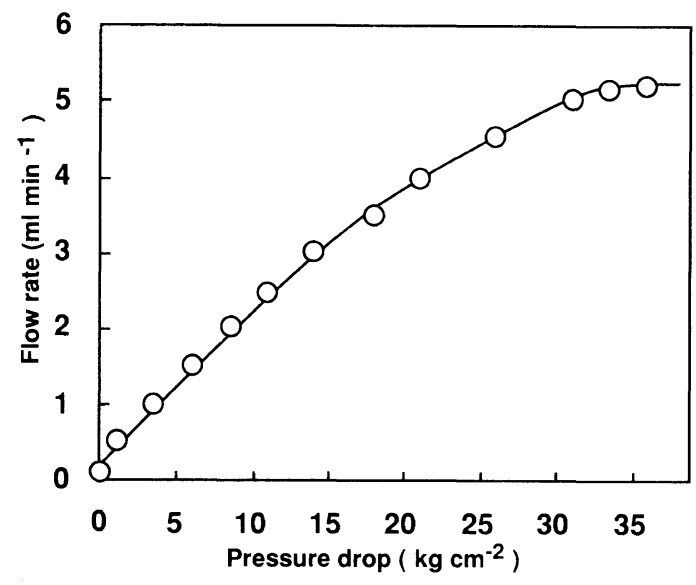

Figure 3. Relationship between flow rate and pressure drop in acetonitrile-water $(60: 40)$.

particles was estimated by the size exclusion chromatography method in tetrahydrofuran. The porosity and exclusion molecular weight of the DAA- 1 and DAA- 4 particles are $38 \%$ and $54 \%$ and 1400 and 7800 (for polystyrene), respectively. The surface area of the particles were determined by BET method: 0.43, 0.21, 0.46 , and $0.28\left(\mathrm{~m}^{2} \mathrm{~g}^{-1}\right)$ in the DAA-1, DAA-2, DAA-3, and DAA-4, respectively.

\section{Physical Stability of Particles}

Figure 3 shows flow rate resistance in the liquid chromatography process estimated in terms of flow rate and pressure drop. The DAA-1 columns showed good linear correlation up to about $3 \mathrm{ml} \mathrm{min}-1$ at the flow rate (i.d. $4.6 \mathrm{~mm}$, eluent: acetonitrile-water $(60$ : 40). This value is satisfactory in HPLC. This good high-flow rate resistance is related to the relatively small swelling degree of the DAA-1 particles. Figure 4 shows the specific swelling degree $\left(S_{\mathrm{d}}\right)$ of DAA-1 particles and Asahipak ODP (most widely used as a totally organic RPLC packing) in benzene, tetrahydrofuran, acetonitrile and methanol. A smaller change of $S_{\mathrm{d}}$ value was observed in the DAA-1 particles.

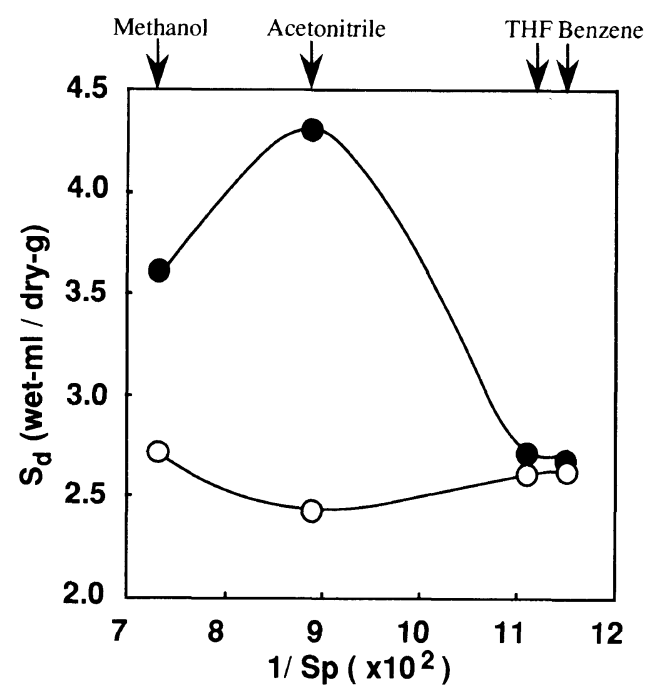

Figure 4. Specific swelling degree $\left(S_{\mathrm{d}}\right)$ of DAA-1 $(-\bigcirc-)$ and Asahipak ODP (- - ) particles.

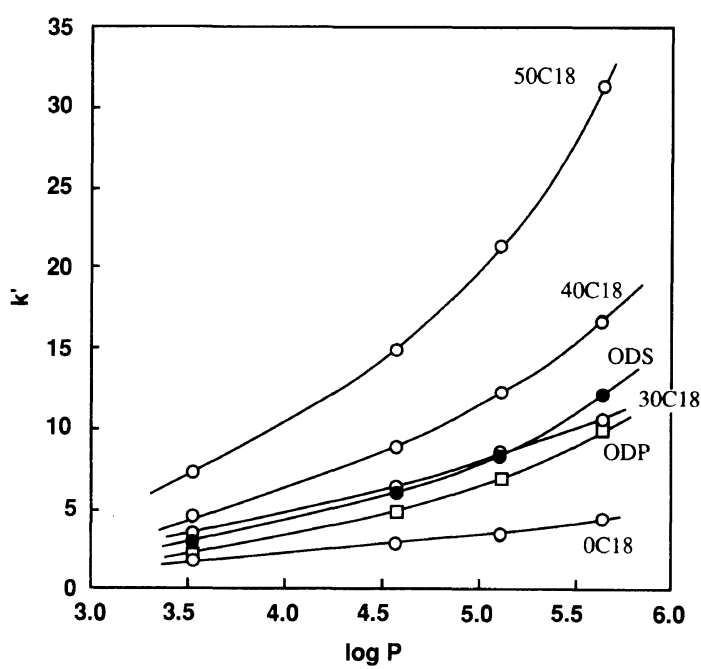

Figure 5. Relationship between capacity factor and $\log P$ for alkanes.

\section{Chromatographic Property}

Retention Capacity $\left(k^{\prime}\right)$ of $N, N$-Dialkylacrylamide Polymer Particles. $k^{\prime}$ values were calculated as $k^{\prime}=\left(V_{\mathrm{r}}-V_{0}\right) / V_{0}$, where $V_{\mathrm{r}}$ is retention volume of the analyte and $V_{0}$ is average of acetonitrile and glycerine. As shown in Figure 5, a close correlation between the $k^{\prime}$ value and hydrophobic parameter 


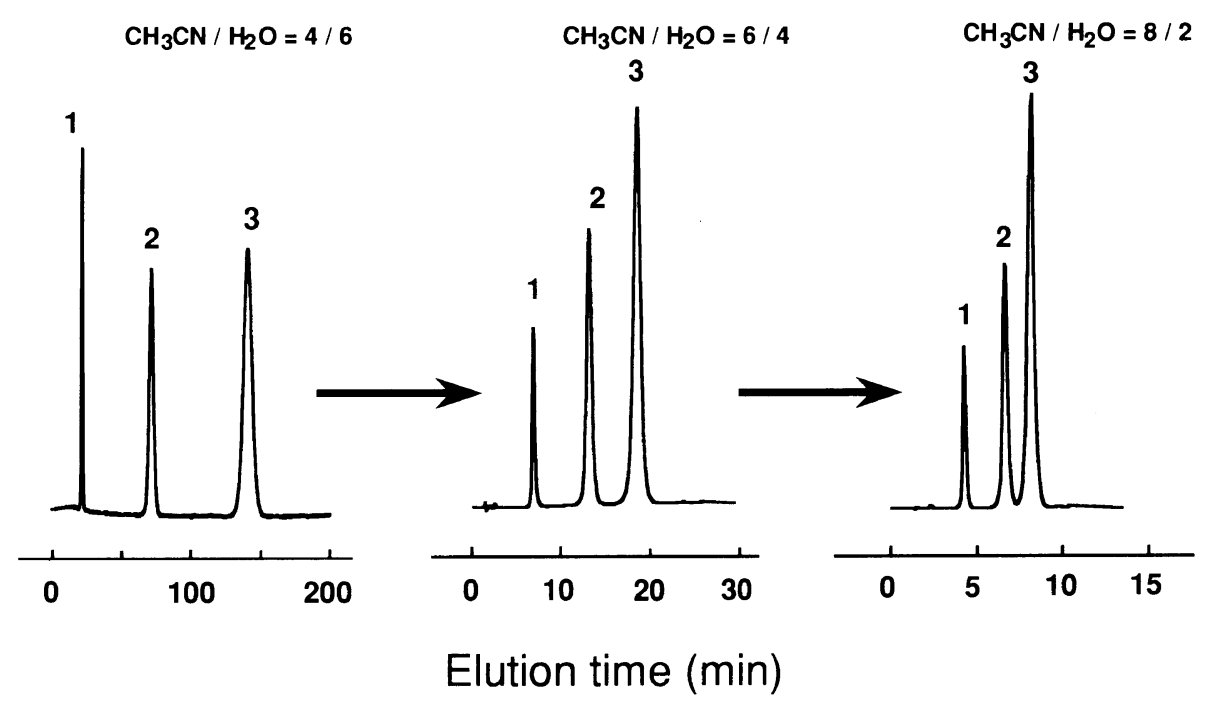

Figure 6. Chromatograms for aromatic compounds in acetonitrile-water: $1=$ benzene; 2 =naphthalene; $3=$ fluorene.

$(\log P)$, calculated according to the method of Rekker, ${ }^{14}$ was observed for synthetic packings as well as for commercial packings, octadecylated silica gels (ODS) and Asahipak ODP. $k^{\prime}$ value also increased with increasing molar ratio of $\mathrm{C}_{18} \mathrm{C}_{1}$-AA in the suspension. This shows that the hydrophobicity of the packings is directly related to $\mathrm{C}_{18} \mathrm{C}_{1}$ - $\mathrm{AA}$ content and the retention ability is easily controllable by adjusting the monomer ratio of the suspension.

Figure 6 shows chromatograms for aromatic compounds in acetonitrile-water. It is evident that increasing the organic content of the mobile phase reduces retention: analysis time is lowered by raising the proportion of acetonitrile in the eluent. In addition, no significant change in peak shape or column efficiency was observed, regardless of change in mobile phase composition. This is related to the small change in swelling degree in various solvents.

\section{RPLC of Carbonyl and Aromatic Compounds}

Figure 7 shows examples of the relationship between $k^{\prime}$ measured in acetonitrile-water and $\log P$ of aromatic compounds. Higher retention strength was observed for the $N, N$ -

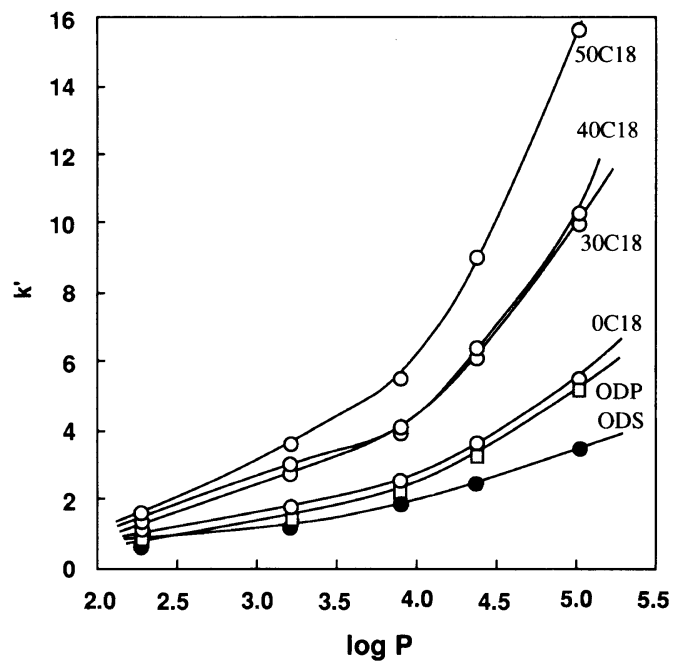

Figure 7. Relationship between capacity factor and carbon number for aromatic compounds. Solutes: benzene, naphthalene, fluorene anthracene, and pyrene.

dialkyl type particles than for ODS packings, although the elution order obeyed an RPLC mode. These results show that $N, N$-dialkyl type packings have weak affinity including interactions for aromatic molecules as well as hydrophobic interactions. Such affinity is often related to the rigidity of sample mole- 
A

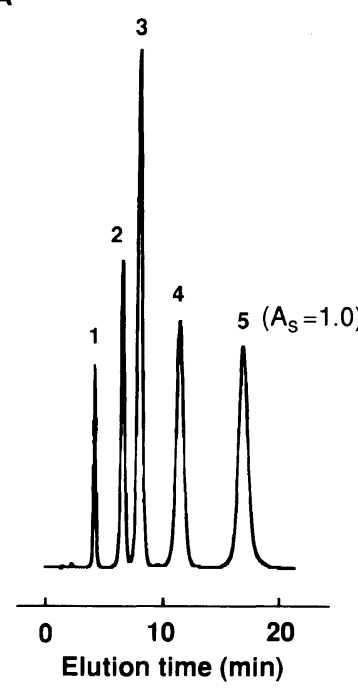

B

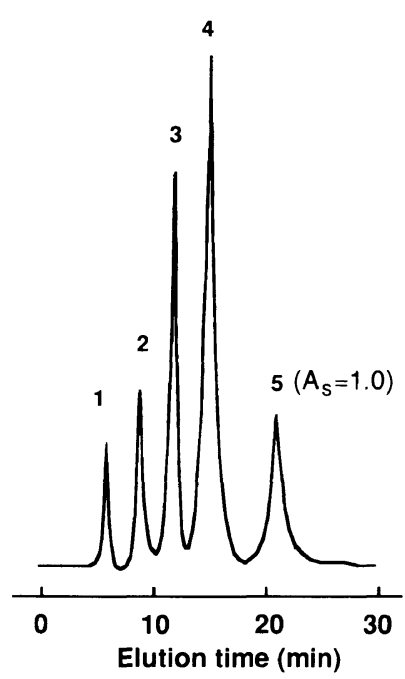

C

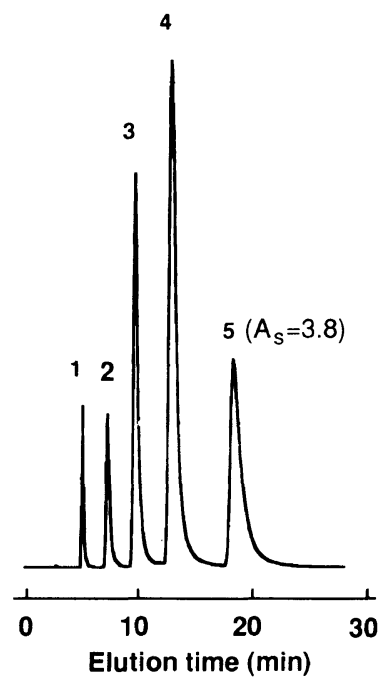

Figure 8. Separation of alkylbenzoates with DAA-1 (A), AMA-1 (B), and Asahipak ODP (C) columns: $1=$ benzene; 2 =naphtharene; $3=$ fluorene; $4=$ anthracene; $5=$ pyrene.

cules. It is known that polymer packings with micropores show more excessive retention for rigid and compact molecules such as anthracene and pyrene than for flexible molecules such as alkanes. ${ }^{15}$ Therefore, peak shapes for aromatic compounds were compared among polymer packings. Figure 8 shows the separations of some aromatic compounds with the $\mathrm{N}$-alkyl type, $\mathrm{N}, \mathrm{N}$ dialkyl type and Asahipak ODP packings. Asymmetry factors $\left(A_{\mathrm{s}}\right)^{16}$ measured for pyrene at $10 \%$ of the peak height were 1.0, 1.0, and 3.8, respectively: Asahipak ODP showed typical peak tailing. This undesirable peak tailing of Asahipak ODP packings is derived from aromaticity of triallyl isocyanurate used as a crosslinking agent. Both $N$-alkyl and $N, N$ dialkyl type packings showed good symmetrical peaks as both packings have no aromatic rings of solutes.

Figure 9 shows chromatograms for alkyl benzoates using $N$-alkyl and $N, N$-dialkyl type packings. Both elution orders also obeyed an RPLC mode. However, $N$-alkyl type packings showed typical peak tailing. In contrast, $N, N$-dialkyl type packings showed no peak tailing for carbonyl compounds. The asymmetry factors $\left(A_{\mathrm{s}}\right)$ measured for hexyl benzoate at $10 \%$ peak height were 1.0 and 2.0 in $N, N$-dialkyl type and $N$-alkyl type, respectively. The peaks in the $N, N$-dialkyl type packings corresponded to the efficiencies of those for aromatic compounds. These results strongly suggest that there are no amide protons in the $N, N$-dialkyl type packings resulting in the lack of hydrogen bonding interactions for carbonyl compounds.

\section{Retention Capacity of Basic Substances}

The limited use of alkyl bonded silica gels for basic compounds is due to the residual silanol groups and it is very important to check if $N, N$-dialkyl type packings are applicable to RPLC of basic compounds. Figure 10 compares the peak shapes of basic substances from the ODS and the DAA-1 packings. Pyridine was eluted from DAA-1 with symmetrical peak packings, although it was eluted with peak-tailing from the ODS column. Such peak tailing is often observed for comparably strong basic substances in the case of silica bonded packings. Table III summa- 

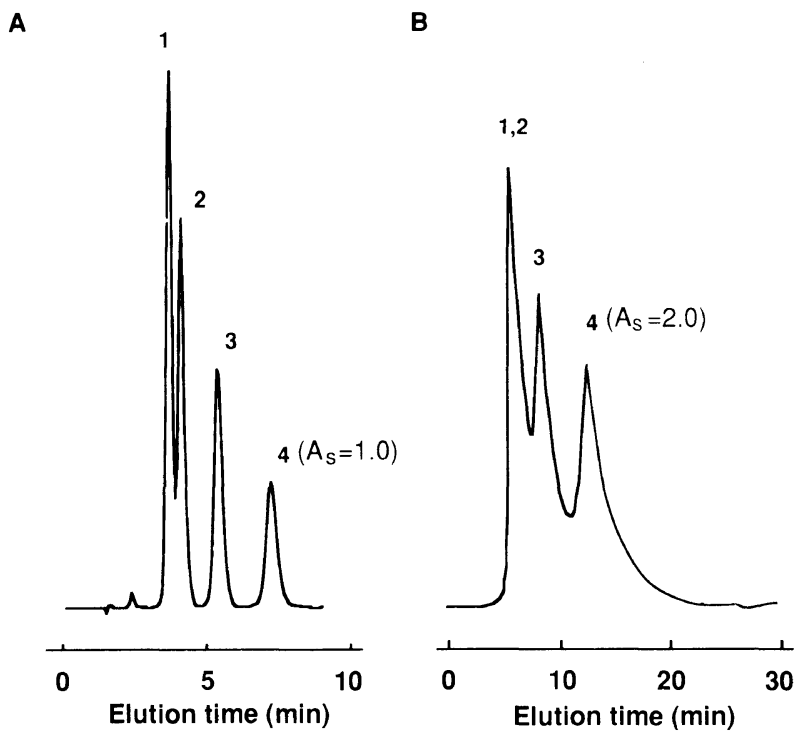

Figure 9. Separation of alkylbenzoates with DAA-1 (A) and AMA-1 (B) columns: 1=methylbenzoate; $2=$ ethylbenzoate; 3 =butylbenzoate; 4 =hexylbenzoate. Eluent, acetonitrile-water $(80: 20)$; flow rate, $0.5 \mathrm{ml} \mathrm{min}^{-1}$.
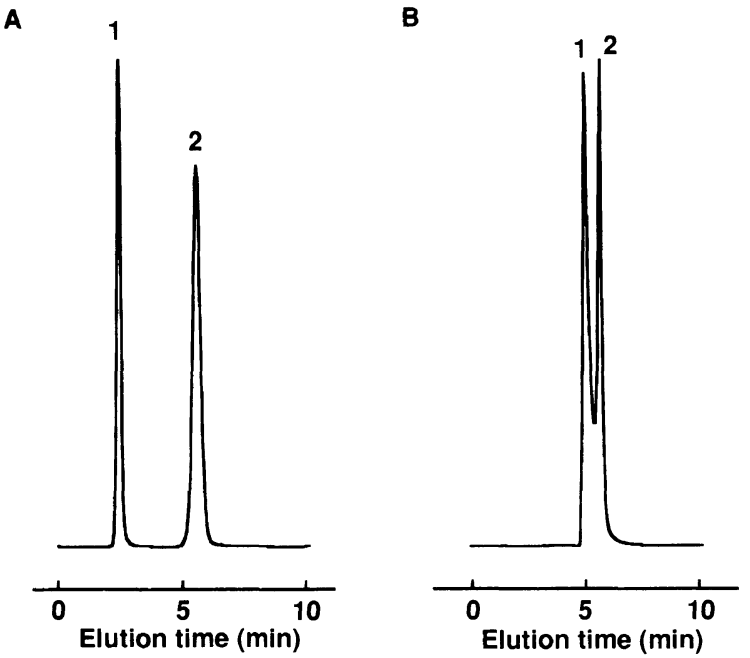

Figure 10. Separation of basic compounds with DAA-1 (A) and ODS (B) columns: $1=$ aniline; $2=$ pyridine. Eluent, acetonitrile-water $(60: 40, \mathrm{v} / \mathrm{v})$; flow rate, $0.5 \mathrm{ml} \mathrm{min}^{-1}$.

rizes a comparison of elution behavior for basic compounds. The ODS and octylated silica gels (OS) packings showed peak tailing for quinoline and $\alpha$-naphthoquinoline, and adsorbed benzyl amine. The excellent properties of the $N, N$-dialkyl type packings are due to the totally organic polymers prepared using nonionic monomers. On the other hand, Asahipak ODP is also prepared using nonionic monomers. However, it is known that 
Table III. Retention behavior of substances

\begin{tabular}{lcccccc}
\hline \multirow{2}{*}{ Solute } & \multicolumn{9}{c}{$k^{\prime}$} \\
\cline { 2 - 7 } & ODS & ODS-TMS & ODP & \multirow{2}{*}{$30 \mathrm{C} 18$} & \multirow{2}{*}{$40 \mathrm{C} 18$} & $50 \mathrm{C} 18$ \\
\hline Pyridine & $1.37(\mathrm{t})^{\mathrm{a}}$ & $-0.06(\mathrm{t})$ & $0.20(\mathrm{t})$ & 0.21 & 0.21 & 0.29 \\
Quinoline & $1.16(\mathrm{t})$ & -0.03 & $0.45(\mathrm{t})$ & 0.53 & 0.61 & 0.7 \\
$\alpha$-Naphthoquinoline & 1.81 & 0.35 & $1.69(\mathrm{t})$ & 2.4 & 2.88 & 3.55 \\
Benzylamine & Not eluted & $0.33(\mathrm{t})$ & $1.01(\mathrm{t})$ & 0.16 & 0.41 & 0.37 \\
\hline
\end{tabular}

${ }^{a}(t)$ : peak tailing.

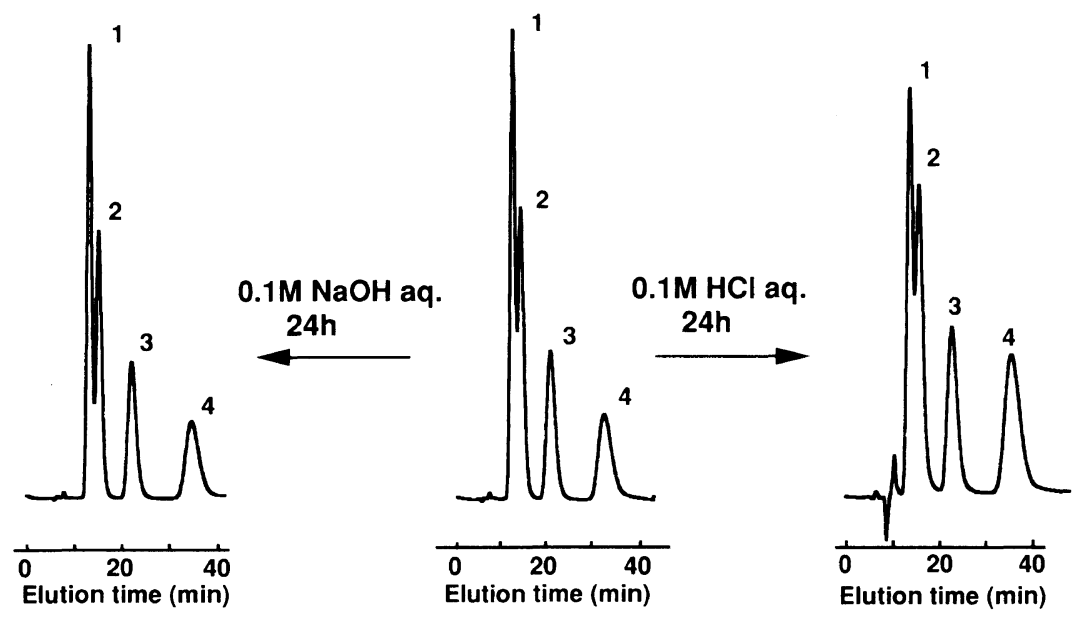

Figure 11. Chromatograms obtained with the DAA-1 columns before and after exposure of alkaline and acidic solutions. Eluent, acetonitrile-warter $(80: 20)$; flow rate, $0.2 \mathrm{ml} \mathrm{min}^{-1}$.

Table IV. HETP of the columns

\begin{tabular}{lccc}
\hline & \multicolumn{3}{c}{ HETP $/ \times 10^{3}$} \\
\cline { 2 - 4 } Solute & ODS & DAA-1 & ODP \\
\hline Pyrene & 4.61 & 6.68 & 9.24 \\
Hexylbenzoate & 5.38 & 5.63 & 6.75 \\
Pyridine & 270 & 180 & 470 \\
\hline
\end{tabular}

Asahipak ODP shows peak tailing for basic compounds. This is due to the carboxylic groups by-produced in the process of introduction of octadecyl group. ${ }^{17,18}$ Dawkins et al. reported octadecylated acrylamide polymer particles for RPLC. ${ }^{8,9}$ The bonded phase was introduced by forming strongly nucleophilic amide anions on the surface of treatment with $\mathrm{N}$-octadecyl bromide. There- fore, the strong base most likely creates a risk of partial hydrolysis of $\mathrm{CONH}$ moieties to produce undesirable anionic groups.

\section{Comparison of HETP}

HETP,${ }^{19}$ a reciprocal of the theoretical plate number, is useful to compare the resolution ability of columns. Table IV summarizes HETP values of the DAA-1, ODS, and Asahipak ODP columns determined using pyrene, hexyl benzoate and pyridine as solutes and acetonitrile-water $(60: 40)$ as an eluent. The DAA-1 column showed good HETP values for all samples.

\section{Acid and Alkaline Resistances}

Conventional alkyl-bonded silica gels and alkyl-bonded polymer particles are generally 
known to decrease rapidly in efficiency in solutions of high and low $\mathrm{pH} .^{20-23}$ Therefore, the acid and alkaline resistances of the $N, N$ dialkyl type packings were examined with aqueous eluents having high and low $\mathrm{pH}$. Figure 11 shows chromatograms obtained for methyl, ethyl, butyl and hexyl benzoates with $N, N$-dialkyl type packings before and after their exposures to $0.1 M \mathrm{NaOH}$ and $0.1 M$ $\mathrm{HCl}$ aqueous solutions, respectively. No significant change in peak shape and column efficiency occurred in either instance. These results indicate that the $N, N$-dialkyl type packings withstand use at $\mathrm{pH} 1-13$ and extend operating $\mathrm{pH}$ in RPLC.

\section{CONCLUSIONS}

The following conclusions can be drawn on the nature and characterization of $\mathrm{N}, \mathrm{N}$ dialkylacrylamide monomers and their polymer particles: (1) the melting point of $N, N$ dialkylacrylamide (or methacrylamide) is much lower than the conventional $N$-monoalkylacrylamide (or methacrylamide). This property is advantageous for aqueous suspension copolymerization. (2) N,N-Dialkylacrylamide is polymerizable, although the corresponding methacrylamide derivatives are inactive because of steric hindrance around the double bonding. (3) The spherical particles are made by one-step copolymerization of $N, N$-dialkylacrylamide. (4) The hydrophobicity of the particles is easily adjusted by changing the molar ratio of the monomers. (5) The column with the $N, N$-dialkylacrylamide particles showed normal RPLC separation for ionic, carbonyl and aromatic compounds. These excellent chromatographic properties of the packing derive from the totally organic nature of the monomers, in that they do not have amide proton, ionic or aromatic groups. (6) $\mathrm{C}-\mathrm{C}$ and $\mathrm{C}-\mathrm{N}$ bondings in $N, N$-dialkylacrylamide polymers are more stable in acid and alkaline solutions than $\mathrm{Si}-\mathrm{O}-\mathrm{C}$ or $\mathrm{CO}-\mathrm{O}$ bondings in conventional packings.

\section{REFERENCES}

1. R. K. Gilpin and M. F. Burke, Anal. Chem., 45, 1383 (1973).

2. N. Tanaka, Kagaku no Ryoiki, 37, 33 (1983).

3. K. Kimata, K. Iwaguchi, S. Onishi, K. Jinno, R. Eksteen, K. Hosoya, M. Araki, and N. Tanaka, J. Chromatogr. Sci., 27, 721 (1989).

4. Y. Ohtsu, Y. Shiojima, K. Koyama, K. Nakamura, O. Nakata, and K. Noguchi, J. Chromatogr., 481, 147 (1989).

5. R. M. Smith and D. R. Garside, J. Chromatogr., 407, 19 (1987).

6. S. Coppi, A. Betti, and C. Bighi, J. Chromatogr., 442, 97 (1988).

7. Y. Yanagihara, K. Noguchi, and M. Honda, Japanese Patent, 1-15822 (1989).

8. J. V. Dawkins and N. P. Gabott, Polymer, 291 (1981).

9. J. V. Dawkins, N. P. Gabott, L. L. Lloyd, J. A. McConville, and F. P. Warner, J. Chromatogr., 452, 145 (1988).

10. K. Suzuki, K. Nakazato, and T. Takasaki, Nippon Kagaku Kaishi, 1327 (1979).

11. K. Nakazato, K. Suzuki, and T. Takasaki, Macromolecules, 23, 1800 (1990).

12. C. Hirayama, K. Yamaguchi, and K. Motozato, Kobunshi Ronbunshu, 40, 441 (1983).

13. C. Hirayama, K. Yamaguchi, K. Matsumoto, and Y. Motozato, Kobunshi Ronbunshu, 40, 547 (1983).

14. N. Tanaka, T. Ebata, K. Hashizume, K. Hosoya, and M. Araki, J. Chromatogr., 475, 195 (1989).

15. R. F. Rekker, "The Hydrophobic Fragmental Constant," Elsevier, Amsterdam, 1977.

16. R. G. Baum, R. Saetre, and F. F. Cantwell, Anal. Chem., 52, 15 (1980).

17. N. Tanaka, K. Hashizume, and M. Araki, Advances in Chromatography, 30, 81 (1989).

18. K. Noguchi, Y. Yanagihara, M. Kasai, and N. Hirata, J. Chromatogr., 506, 145 (1990).

19. A. J. P. Martin and R. L. M. Synge, Biochem. J., 35, 1358 (1941).

20. T. Ohtani, Y. Tamura, M. Kasai, T. Uchida, Y. Yanagihara, and K. Noguchi, J. Chromatogr., 515, 175 (1990).

21. C. Hirayama, H. Ihara, S. Nagaoka, and H. Makise, Chromatographia, 33, 19 (1992).

22. N. Tanaka, K. Kimata, Y. Mikawa, K. Hosoya, and T. Araki, J. Chromatogr., 13, 535 (1989).

23. H. Engelhardt, H. Löw, W. Eberhardt, and M. Mau $\beta$, Chromatographia, 27, 535 (1989). 